\title{
Effect of Intake of Immune Milk Product on the Fecal Microflora in Healthy Female Volunteers
}

\author{
Naoki Hattori, ${ }^{1}$ Isao Hata, ${ }^{1 *}$ Hisakazu lino ${ }^{2}$ and Tomotari Mıtsuoka ${ }^{3}$ \\ 1 Department of Healthy Food, Kanematsu Wellness Corporation, 1-2-1, Shibaura, Minato-ku, Tokyo 105-8005, Japan \\ ${ }^{2}$ Graduate School, Science for Living System, Showa Women's University, 1-7, Taishido, Setagaya-ku, Tokyo 154-8533, Japan \\ ${ }^{3}$ Professor Emeritus, The University of Tokyo, 2-10-7, Sugano, Ichikawa 272-0824, Japan
}

Received March 31, 2003; Accepted for publication, July 28, 2003

\begin{abstract}
Immune Milk Product (40\% WPI Plus, Whey Protein Isolate Plus) was administered to healthy female volunteers and the effects on the intestinal environment and defecation frequency were examined. A non-Immune Milk Product was used as the control in the experiments. For the investigation of defecation frequency and fecal properties, 60 volunteers were assigned to two groups (30 volunteers each). One group consumed $20 \mathrm{~g}$ of Immune Milk Product daily followed by the control period. The other group consumed $20 \mathrm{~g}$ of Immune Milk Product daily after the control period. Both test period and control period were 3 weeks. Ten volunteers of each group were assigned for the test of intestinal environment. The fecal bacterial flora, fecal pH, water content, and fecal ammonia content were examined. Immune Milk Product did not alter the fecal ammonia content. The percentage of Bifidobacterium in the fecal flora was increased by the intake of Immune Milk Product. The number of Clostridium perfringens (lecithinase-positive) was slightly decreased by the intake of Immune Milk Product after 3 weeks. The defecation frequency was significantly increased by the intake of Immune Milk Product. These results suggest that the intake of Immune Milk Product is effective for improving the intestinal environment, fecal properties, and defecation frequency.
\end{abstract}

Key words: Immune Milk Product; fecal flora; intestinal environment

\section{INTRODUCTION}

Milk contains not only the nutrients essential for the growth of neonatal mammals, but also large amounts of factors needed for host protection from infections (15). Antibodies contained in milk play an important role in the healthy growth of neonates. In the case of humans, antibodies are transmitted from the mother to the fetus via placenta and also in maternal milk. In cattle, however, antibody transmission through placenta is rare, and transmission via the colostrum immediately after birth plays an important role in protecting neonates from infection. Thus, in mammals, antibodies transmitted via maternal milk contribute greatly to protecing neonates from infection.

The "Immune Milk" was developed by Stolle Milk Biologics International (Cincinnati, OH, USA) to provide the antibodies contained in maternal milk to adults for the purpose of preventing disease and promoting health. The following steps are taken to produce it. First, 26 bacterial antigens (Table 1), which colonize or pass through human intestines and cause infection, are processed to reduce their toxicity and make them

*Corresponding author. Mailing address: Department of Healthy Food, Kanematsu Wellness Corporation, 1-2-1, Shibaura, Minato-ku, Tokyo 1058005, Japan. Phone: +81-3-5440-9768. Fax: +81-3-5440-6572. E-mail: isao_hata@kwn.kanematsu.co.jp harmless. These antigens are administered serially to pregnant cows. The cows produce antibodies to the serially administered antigens and release them in large amounts into milk (9). Milk is collected from these cows and skimmed to remove the fat. To prevent inactivation of the antibodies contained therein, the milk is sterilized at a low temperature and spray-dried. In addition, whey protein products are produced. These are composed of whey protein extracted from the milk for the purpose of concentrating the antibodies and for use by those who are intolerant to lactose. The Immune Milk and extracted whey protein products are sold in various flavors and formulations.

Immune Milk has undergone various safety studies and clinical tests, and the safety of this milk product has been sufficiently demonstrated by drinking tests conducted in the United States and Japan for over 40 years. Clinical tests conducted in Japan have shown that the milk suppressed the onset of opportunistic infection by intestine-derived bacteria in irradiated mice (3) and exerted anti-inflammatory action in mouse models of inflammation $(4,6,8,10,14)$. Clinical tests in the United States revealed the reduction of arthralgia associated with rheumatoid arthritis (U.S. Patent No. $4,732,757)$, cholesterol reduction in patients with hypercholesterolemia (1), and hypotensor effects in hypertensive patients (17) following the consumption of 
Table 1. Bacteria used for Immune Milk.

\begin{tabular}{lr}
\hline \multicolumn{1}{c}{ Bacteria } & ATCC* \\
& No. \\
\hline Staphylococcus simulans & 11631 \\
Staphylococcus epidermidis & 155 \\
Streptococcus pyogenes A type 1 & 8671 \\
Streptococcus pyogenes A type 3 & 10389 \\
Streptococcus pyogenes A type 5 & 12347 \\
Streptococcus pyogenes A type 8 & 12349 \\
Streptococcus pyogenes A type 12 & 11434 \\
Streptococcus pyogenes A type 14 & 12972 \\
Streptococcus pyogenes A type 18 & 12357 \\
Streptococcus pyogenes A type 22 & 10403 \\
Aerobacter aerogenes & 884 \\
Escherichia coli & 26 \\
Salmonella enteritidis & 13076 \\
Pseudomonas aeruginosa & 7700 \\
Klebsiella pneumoniae & 9590 \\
Salmonella typhimurium & 13311 \\
Haemophilus influenzae & 9333 \\
Streptococcus mitis & 6249 \\
Proleus vulgaris & 13315 \\
Shigella dysenteriae & 11835 \\
Propionibacterium acnes & 11827 \\
Streptococcus sanguis & 10556 \\
Streptococcus salivarius & 13419 \\
Streptococcus mutans & 25175 \\
Streptococcus agalactiae & 13813 \\
Streptococcus pneumoniae & 6303 \\
\hline$*$ American-typeculture collection & \\
\hline & \\
\hline
\end{tabular}

*American-type culture collection.

this milk. Recent studies have shown that when this milk was consumed by immunologically compromised cancer patients and elderly individuals, the individuals showed fewer adverse reactions to drugs, fewer complications (2), and improved resistance to opportunistic infections (5) thus leading to a better quality of life. The results of tests in humans suggest that these effects of the milk are associated with the intestinal environment in humans, but few direct studies of the effects of the intestinal environment on the action of this milk have been conducted.

The present study was undertaken to examine whether or not the components of Immune Milk improve the intestinal flora and properties of human feces. Thus, changes in the intestinal flora and properties of feces following ingestion of a granular beverage mainly composed of the whey protein of Immune Milk were investigated.

\section{MATERIALS AND METHODS}

1. Test diets. Two test diets (test and control drinks) were used. The test diet was a whey protein product
Table 2. Composition of diets.

\begin{tabular}{lcc}
\hline & Test drink (\%) & Control drink (\%) \\
\hline HiPRO Plus $^{1)}$ & 40.00 & - \\
BiPRO $^{2)}$ & - & 40.00 \\
Dextrin & 31.23 & 31.23 \\
Banana juice & 13.30 & 13.30 \\
Glucose & 13.30 & 13.30 \\
Flavor & 2.17 & 2.17 \\
\hline Total & 100.00 & 100.00 \\
\hline
\end{tabular}

${ }^{1)}$ Whey protein isolate of Immune Milk.

${ }^{2)}$ Whey protein isolate of normal milk.

\begin{tabular}{ll|l|l|l|l|} 
Periods & 1 week & 3 weeks & 2 weeks & 3 weeks & 2 weeks \\
A group & $\begin{array}{l}\text { Pre- } \\
\text { drink }\end{array}$ & Test & $\begin{array}{l}\text { Inter- } \\
\text { val }\end{array}$ & Control & $\begin{array}{l}\text { No } \\
\text { drink }\end{array}$ \\
\hline
\end{tabular}

\begin{tabular}{|c|c|c|c|c|c|}
\hline \multirow[t]{2}{*}{ B group } & $\begin{array}{l}\text { Pre- } \\
\text { drink }\end{array}$ & Control & $\begin{array}{l}\text { Inter- } \\
\text { val }\end{array}$ & Test & $\begin{array}{l}\text { No } \\
\text { drink }\end{array}$ \\
\hline & $\uparrow$ & & $\uparrow$ & & $\uparrow$ \\
\hline Week & 1 & & $6^{\text {th }}$ & & $11^{\mathrm{th}}$ \\
\hline
\end{tabular}

Fig. 1. Experimental schedule.

$\uparrow:$ Whole feces were collected in the last week of each period, respectively.

made from Immune Milk, and the control diet was a whey protein product made from normal milk (nonimmunized cows milk). Both diets were in the form of a banana-flavored granular drink. Table 2 shows the composition of each diet. These raw materials were mixed and granulated. Each pack $(20 \mathrm{~g})$ was dissolved in water immediately before it was drank.

2. Subjects. Sixty healthy female volunteers attending universities in Tokyo (mean age: $19.3 \pm 0.8$ years) were enrolled into the study. According to the rules of the Helsinki Declaration, each candidate was given accounts of the purpose and details of the study. Informed consent was obtained from each of the 60 subjects. Candidates whose condition was poor (due to illness, etc.) or who were on drug therapy were excluded from the study.

3. Test schedule and method of data collection. The test lasted for 11 weeks (Fig. 1). The experimental period was composed of a pre-drink period (1 week), a test period ( 3 weeks), an interval period ( 2 weeks), a control period ( 3 weeks) and a no-drink period (last 2 weeks). Throughout the experimental period, subjects were prohibited from ingesting yogurt, foods containing lactobacilli, foods containing oligosaccharides and 
Natto (fermented soybeans). No restriction was imposed on other foods or other aspects of daily living. With regard to defecation, each subject was asked to fill in a questionnaire containing two questions (frequency and amount of defecation) every day. The amount of feces was expressed by how many ping pong balls would be equivalent to the total amount of feces evacuated every day. Questionnaire surveys were also conducted for information on physical condition, meals, drug therapy, alcohol consumption, and subjective abdominal symptoms.

4. Collection of feces and checks for intestinal flora. From the 60 subjects (mean age: $19.3 \pm 0.8$ years), 11 students who had a tendency of constipation (18) were selected (mean age: $19.4 \pm 0.9$ years). The fecal samples from these 11 subjects were examined for fecal flora. The examinations were conducted using the method of Mitsuoka (7). Samples were examined for the following bacteria: Bifidobacterium, Bacteroidaceae, Clostridium (lecithinase-negative), Clostridium (lecithinasepositive), Enterobacteriaceae, and Eubacterium. BL agar medium (BL, Nissui Pharmaceutical Co., Ltd., Tokyo, Japan) and EG agar medium (EG, Nissui Pharmaceutical Co., Ltd., Tokyo, Japan) were used for the detection of anaerobic bacteria. Trypticase soy blood agar (TS, BBL) was used for the detection of aerobic bacteria. Samples on TS media were incubated under aerobic conditions at $37^{\circ} \mathrm{C}$ for $24 \mathrm{hr}$. Samples on the other media were incubated under anaerobic conditions at $37^{\circ} \mathrm{C}$ for $48 \mathrm{hr}$ using an Aneropack (Mitsubishi Gas Chemical Co., Ltd., Tokyo, Japan). Selective media used were BS (for the detection of Bifidobacterium), NBGT (for Bacteroidaceae), CW (for Clostridium), ES (Eubacterium), and DHL (for Enterobacteriaceae, Nissui Pharmaceutical Co., Ltd., Tokyo, Japan). The counts of bacteria on BL and EG were deemed to be the total anaerobic bacterial count. Counts on TS were deemed to be the total aerobic bacterial count. In addition to counting bacteria in each medium, simplified bacterial identification was conducted on the basis of evaluating the morphological features of colonies and bacterial cells and responses to Gram staining.

5. Fecal $p H$, moisture and ammonia level. The feces of the same 11 students selected for collection of feces and checking of intestinal flora were used. Fecal $\mathrm{pH}$ levels were measured with a $\mathrm{pH}$ meter B-112 (Horiba, Ltd., Kyoto, Japan), with the electrode placed directly in contact with each fecal sample.

Fecal water content was measured by calculating the decrease in the weight of precisely $1.0 \mathrm{~g}$ feces after vacuum freeze-drying.

Fecal ammonia content was measured as follows. One gram of feces was combined with $4 \mathrm{ml}$ of $2 \%$ perchloric acid and agitated well. The mixture was then shaken for $60 \mathrm{~min}$. The sample was centrifuged $(2,000$ $\times g, 5 \mathrm{~min}$ ) and the supernatant was harvested. The precipitate was combined with $2 \mathrm{ml}$ of $2 \%$ perchloric acid and the mixture was subjected to a further 60-min shaking. After the same procedure was repeated again, the collected supernatants were combined and centrifuged $(20,000 \times g, 20 \mathrm{~min})$. The ammonia content in $10 \mathrm{ml}$ of the supernatant was measured using the Ammonia Test Wako (Wako Pure Chemical, Osaka, Japan).

6. Statistical analysis. The values of each parameter were expressed as mean \pm S.D. Student's $t$-test was used to test the significance of differences.

\section{RESULTS}

\section{Effects on the Defecation Frequency and Fecal Vol- ume}

Effects on defecation frequency and fecal volume are shown in Table 3. (Intake of the test diet significantly increased the frequency of defecation as compared to the pre-drink period.) The defecation frequency in the pre-drink period increased in the test period $(3.9 \pm 1.1$ vs $4.5 \pm 1.7)$. Additionally, the fecal volume increased in the test period (11.4 \pm 1.1 vs $13.9 \pm 1.2)$.

\section{Changes in Fecal Bacterial Flora}

The changes in fecal bacteria count are shown in Table 4. The log number of Lactobacillus in the test period was one order in magnitude larger than that in

Table 3. Effects of intake of Immune Milk Product on defecation conditions.

\begin{tabular}{lrrrrr}
\hline \multirow{2}{*}{ Conditions } & \multicolumn{5}{c}{ Period } \\
\cline { 2 - 5 } & \multicolumn{1}{c}{ Pre-drink } & \multicolumn{1}{c}{ Test } & \multicolumn{1}{c}{ Interval } & \multicolumn{1}{c}{ Control } & \multicolumn{1}{c}{ No drink } \\
\hline Frequencyl) & $3.9 \pm 1.1$ & $4.5 \pm 1.7$ & $4.3 \pm 1.2$ & $4.8 \pm 1.6$ & $4.1 \pm 1.4$ \\
Fecal volume ${ }^{2)}$ & $11.4 \pm 1.1$ & $13.9 \pm 1.2$ & $13.4 \pm 1.0$ & $15.9 \pm 1.7$ & $14.6 \pm 1.7$ \\
\hline $\begin{array}{l}\text { Date indicates mean } \pm \text { S.D. } \\
\text { 1) Times per week. }\end{array}$ \\
2) Fecal volume is scored as the number of ping pong balls.
\end{tabular}


Table 4. Changes in intestinal flora of each bacteria to total count in the feces.

\begin{tabular}{lrrrrr}
\hline & \multicolumn{5}{c}{ Period } \\
\cline { 2 - 6 } & Pre-drink & \multicolumn{1}{c}{ Test } & Interval & Control & No drink \\
\hline $\begin{array}{l}\text { Clostridium } \\
\quad \text { (lecithinase-positive) }\end{array}$ & $2.9 \pm 2.9$ & $0.0 \pm 0.0$ & $2.3 \pm 2.3$ & $0.0 \pm 0.0$ & $2.1 \pm 2.1$ \\
$\begin{array}{c}\text { Clostridium } \\
\quad(\text { lecithinase-negative) }\end{array}$ & $8.4 \pm 0.8$ & $9.0 \pm 0.3$ & $8.5 \pm 0.4$ & $8.8 \pm 0.2$ & $8.6 \pm 0.3$ \\
Bacteroidaceae & $10.2 \pm 0.4$ & $10.0 \pm 0.5$ & $10.1 \pm 0.3$ & $10.0 \pm 0.5$ & $10.1 \pm 0.4$ \\
Eubacterium & $9.5 \pm 0.5$ & $9.6 \pm 0.3$ & $9.7 \pm 0.3$ & $9.6 \pm 0.3$ & $9.7 \pm 0.5$ \\
Bifidobacterium & $9.5 \pm 0.3$ & $9.8 \pm 0.2$ & $9.6 \pm 0.2$ & $9.7 \pm 0.3$ & $9.6 \pm 0.2$ \\
$\quad$ Lactobacillus & $6.1 \pm 1.4$ & $7.3 \pm 0.8$ & $6.0 \pm 2.2$ & $7.3 \pm 0.7$ & $6.1 \pm 1.8$ \\
Enterobacteriaceae & $7.5 \pm 1.1$ & $6.0 \pm 1.2$ & $7.0 \pm 1.2$ & $6.4 \pm 1.2$ & $6.9 \pm 1.4$ \\
\hline
\end{tabular}

Mean \pm S.D. of log number of bacteria/g wet feces.

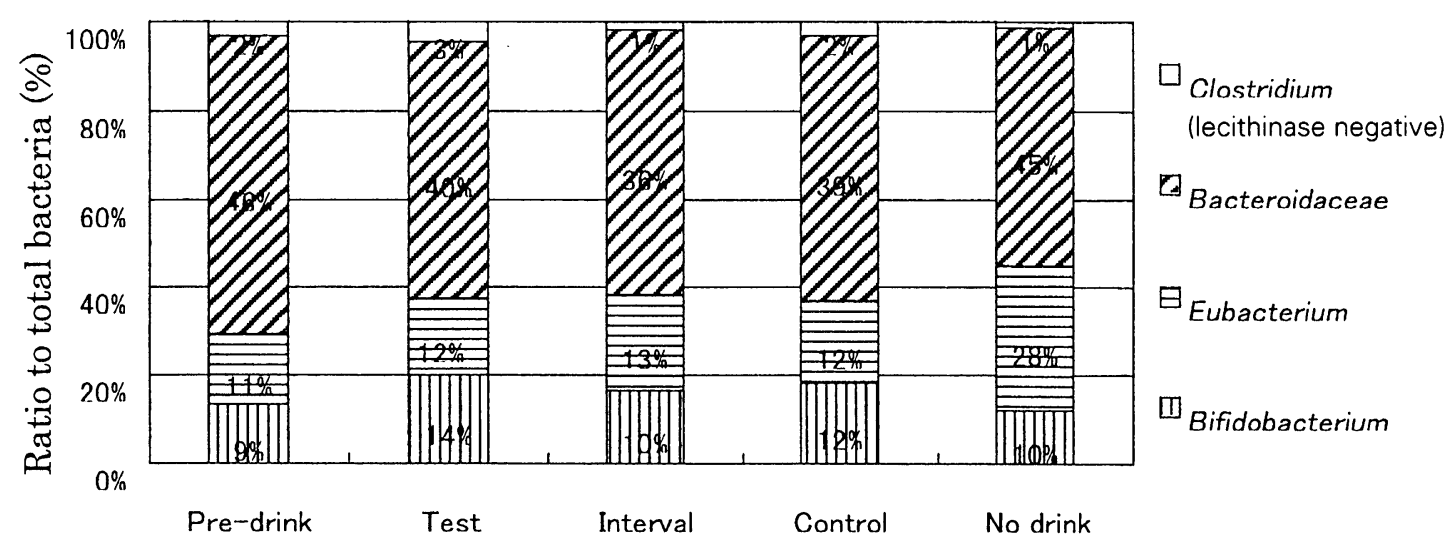

Fig. 2. Effect on the intestinal flora of volunteers following the consumption of Immune Milk.

Table 5. Effect of intake of Immune Milk Product on fecal pH, ammonia and water contents.

\begin{tabular}{lccccc}
\hline & \multicolumn{5}{c}{ Period } \\
\cline { 2 - 6 } & Pre-drink & Test & Interval & Control & No drink \\
\hline $\mathrm{pH}$ & $6.41 \pm 0.12$ & $6.22 \pm 0.11^{*}$ & $6.40 \pm 0.13$ & $6.25 \pm 0.11^{*}$ & $6.39 \pm 0.12$ \\
Ammonia $(\mu \mathrm{mol} / \mathrm{g})$ & $787.73 \pm 155.42$ & $454.27 \pm 91.22^{*}$ & $728.00 \pm 153.65$ & $511.73 \pm 109.80^{*}$ & $700.45 \pm 222.94$ \\
Water content $(\%)$ & $72.35 \pm 2.49$ & $76.13 \pm 1.66^{*}$ & $71.30 \pm 2.19$ & $74.56 \pm 1.72$ & $71.95 \pm 2.89$ \\
\hline
\end{tabular}

Data indicates mean \pm S.D.

${ }^{*} p=0.05 ;$ statistically significant difference from the pre-drink period.

the pre-drink period $(7.3 \pm 0.8$ vs $6.1 \pm 1.4)$. However, the log number of Clostridium perfringens in the test period was two order in magnitude smaller than that in the pre-drink period $(0.0 \pm 0.0$ vs $2.9 \pm 2.9)$.

On the other hand, the change in the ratio (\%) of each bacterial group as compared to the total bacteria is shown in Fig. 2. The percentage of Bifidobacterium increased significantly during the test period (14\%) when compared with the pre-drink (9\%) and interval periods (10\%). The percentage of $C$. perfringens among the total bacterial flora decreased significantly during the test period $(0 \%)$, and this decrease was particularly marked when compared with the pre-drink period (2\%). The total bacterial flora decreased significantly during the test period, and this decrease was particularly marked when compared with the pre-drink period.

\section{Effects on Fecal pH, Ammonia, and Water Contents}

Effects on fecal $\mathrm{pH}$, ammonia, and water contents are shown in Table 5. Both $\mathrm{pH}$ and ammonia contents 
in feces decreased significantly during the test and control periods as compared to the other periods. Fecal water content tended to increase following intake of the test diet.

\section{DISCUSSION}

Intestine-modulating effect refers to improvement in the intestinal flora, decrease in the products of putrefaction remaining in the intestine, and improvement of feces (18). The present study was undertaken to evaluate the effects of Immune Milk and its derivative products on fecal bacterial flora and other features of feces in female university students. The ingestion of extracts from Immune Milk resulted in a significant increase in intestinal counts of Bifidobacterium, suggesting that the extract from Immune Milk is useful for improving the intestinal flora.

In recent years, it has been reported that fermented milk and other beverages, produced using lactobacilli, as well as oligosaccharides work to modulate intestinal function $(11,13)$. If a lactobacillus beverage is ingested, the lactobacilli reaching the intestine decompose the simultaneously ingested lactose and colonize the intestine, and the lactic acid which is produced during the course of decomposition of sugars (e.g., lactose) promotes modulation of the intestinal function. Studies are also underway to investigate the role played by sugars such as oligosaccharides as factors activating intestinal bacteria. Immune Milk is a food that contains antibodies. It is expected to modulate the intestinal function through a mechanism which differs from those by which lactobacilli and oligosaccharides modulate intestinal function. In general, antibodies are host defense factors that are closely involved in protection against infection in higher animals. Since newborn infants are poorly protected against infection, the mother's antibodies are passed to them in the breast milk. These antibodies are among the major infection protection factors contained in cow's milk. Antibodies are highly specific against pathogenic microorganisms. The main component of antibodies in cow's Milk is IgG, consisting of IgG1 and $\operatorname{IgG} 2$ at a ratio of $9: 1$, and the predominant IgG1 is selectively transferred from the blood. In addition, IgG1 resists thermal sterilization and the actions of peptic enzymes. It has been suggested that IgG1 modifies the intestinal flora (16).

The results of this study clearly show that the test diet derived from Immune Milk improved the intestinal flora more markedly than the control diet from normal milk. This probably reflects the fact that the antibodies contained in Immune Milk improved the intes- tinal flora.

The present study was conducted on female university students. In recent years, women living alone (especially students) have tended to go on low-calorie intake diets excessively. We therefore anticipated before the start of this study that drawing conclusions with regard to particular tendencies would be difficult because of such dietary habits. In fact, however, the intestinal lactobacilli count increased markedly after the intake of Immune Milk Product in the present study. This suggests that the antibodies contained in Immune Milk stimulate the growth of beneficial bacteria and eradicate harmful bacteria. It is necessary to examine these effects further in a population having better-controlled dietary habits. It is also desirable that the mechanism for the changes in the intestinal flora observed in this study be clarified.

Acknowledgments. We are indebted to ORTHO Corporation (Tokyo, Japan) for supplying the bananaflavored granular drinks used in this study.

\section{REFERENCES}

(1) Galay A, Ferrara J-M, Felber J-P, Schneider H. 1990. Cholesterol-lowering effect of skim milk from immunized cows in hypercholesterolemic patients. Am J Clin Nutr 52: 1014 1019.

(2) Ikematsu H. 2000. Experience of "Immune Milk" tablets in elderly. Diagn Treat 88: 1945-1948.

(3) Ishida A, Yoshikai Y, Murosaki S, Hidaka Y, Nomoto K. 1992. Adoministration of milk from cows immunized with intestinal bacteria protects mice from radiation-induced lethality. Biotherapy 5: 215-225.

(4) Ishida A, Yoshikai Y, Murosaki S, Kubo C, Hidaka Y, Nomoto K. 1992. Consumption of milk from cows immunized with intestinal bacteria influences age-related changes in immune competence in mice. J Nutr 122: 1875-1883.

(5) Kobayashi M, Setoyama O, Ishigaki Y. 1999. Effect of "Immune Milk" tablets on QOL and various symptoms in advanced cancer patients. Ther Res 20: 3187-3192.

(6) Kobayashi T, Ohmori T, Yanai M, Kawanishi G, Yoshikai Y, Nomoto K. 1991. Protective effect of orally administering immune milk on endogenous infection in $\mathrm{X}$-irradiated mice. Agric Biol Chem 55: 2265-2272.

(7) Mitsuoka T. 1980. A Color Atlas of Anaerobic Bacteria, Sobun-Press, Tokyo, p. 51-92.

(8) Murosaki S, Yoshikai Y, Kubo C, Ishida A, Matsuzaki G, Sato T, Endo K, Nomoto K. 1991. Influence of intake of skim milk from cows immunized with intestinal antigens on onset of renal disease in $(\mathrm{NZB} \times \mathrm{NZW}) \mathrm{F}_{1}$ mice fed ad libitum or restricted in energy intake. J Nutr 121: 1860 1868.

(9) Nomoto K. 1991. Function and application of "Immune milk." Bio Industry 8: 783-790.

(10) Nomoto K, Matsuoka Y, Hayakawa K, Ohwaki M, Kan T, 
Yoshikai Y, Nomoto K. 1992. Antibacterial effect of bovine milk antibody against Escherichia coli in a mouse indigenous infection model. Med Microbiol Immunol 181: $87-98$.

(11) Ogata T, Nakamura T, Anjitsu K, Yaeshima T, Takahashi S, Fukuwatari Y, Ishibashi N, Hayasawa H, Fujisawa T, Iino H. 1997. Effect of Bifidobacterium longum BB536 administration on the intestinal environment, defecation frequency and fecal characteristics of human volunteers. Bioscience Microflora 16: 53-58.

(12) Ogata T, Takahashi S, Ishibashi N, Hayasawa H, Iino $\mathrm{H}$. 1997. Effect of yogurt containing Bifidobacterium longum BB536 on the intestinal environment, fecal characteristics and defecation frequency: A comparison with standard yogurt. Bioscience Microflora 16: 73-77.

(13) Okazaki M, Fujikawa S, Matsumoto N. 1990. Effect of xylooligosaccharide on the growth of bifidobacteria. Bifidobacteria Microflora 9: 77-86.
(14) Ormrod DJ, Miller TE. 1991. The anti-inflammatory activity of a low molecular weight component derived from the milk of hyperimmunized cows. Agents Actions 32: 160166.

(15) Otani H. 1997. Modification of immuno system by peptides derived from milk caseins. Recent Res Devel Agric Biological Chem 1: 269-289.

(16) Otani H.1998. Production and utilization of bovine milk immunoglobulins specific to pathogenic microorganisms. Milk Science 47: 63-75.

(17) Sharpe SJ, Gamble GD, Sharpe DN. 1994. Cholesterol-lowering and blood pressure effects of immune milk. Am J Clin Nutr 59: 929-934.

(18) Thompson WG, Longstreth GF, Drossman DA, Heaton KW, Irvine E J, Muller-Lissner SA. 1999. Functional bowel disorders and functional abdominal pain. Gut 45: 11431147. 